\title{
Langen Carita Jaka Tingkir Opera Edukasi Anak
}

\author{
R.M. Pramutomo, Slamet MD, Tubagus Mulyadi \\ Institut Seni Indonesia Surakarta \\ Jalan Ki Hadjar Dewantara No. 19, Jebres, Kentingan, Surakarta 57126 \\ Email: rmpram@yahoo.com.sg
}

\begin{abstract}
This article discusses the Java opera called Langen Carita from early 19th century which was used as educational media for the Javanese native. A figure of Hadi Sukatno was firstly trusted by Ki Hadjar Dewantara, a founder of Taman Siswa School, to use a Langen Carita. Specifically, this article deliberates Jaka Tingkir as Langen Carita in its current performance. This article based on qualitative reserach combined with the historical arts method. It uses a heuristic method to validate data and to critisize the sources. The main approach of this article is ethnochoreology according to the materials used in a dance drama as a branch of performing arts studies. Ethnochoreological perspectives are needed to find the basic creation of an opera dance drama in which dance is viewed as a cultural product.
\end{abstract}

Keywords: langen carita, opera, values of education, history

\begin{abstract}
ABSTRAK
Artikel ini mendiskusikan sebuah fenomena opera Jawa yang sejak awal dirancang untuk media pembelajaran bagi para warga pribumi. Sosok Ki Hadi Sukatno yang pertama kali dipercaya oleh Ki Hadjar Dewantara untuk menggunakan media Langen Carita. Secara khusus, artikel ini membahas Langen Carita Joko Tingkir di masa kini. Kajian artikel ini bersifat kualitatif, dengan menggunakan metode sejarah seni. Sebagaimana dalam metode sejarah, maka di dalam sejarah seni sifat data kualitatif itu dicermati melalui kritik sumber. Langkah kritis ini lazim disebut sebagai langkah heuristik pada metode sejarah. Hal ini dilakukan untuk mendapatkan sebuah objektivitas pada kajian. Selain itu, pendekatan utama dalam pengkajian ini adalah pendekatan etnokoreologi. Pendekatan ini lazim dilakukan dalam spesifikasi metode sejarah seni yang agak berbeda dengan metode sejarah. Pendekatan etnokoreologi adalah pendekatan dengan menempatkan kedudukan tari sebagai objek multidimensional. Dikarenakan objek tari adalah multidemensi, maka diperlukan pengkajian setiap sisi dimensi yang ada pada objeknya. Etnokoreologi secara metodologis cocok untuk melihat Langen Carita sebagai genre dramatari sebagai sebuah produk budaya.
\end{abstract}

Kata kunci: langen carita, opera, nilai edukasi, sejarah 


\section{PENDAHULUAN}

Pada pendahuluan artkel ini perlu didahului dengan sejenak mengungkap fenomena kesadaran terhadap pendidikan bagi anak pribumi di awal tahun 1930-an. Sejarah kota Yogyakarta pernah lahir Perguruan Taman Siswa yang didirikan oleh Ki Hadjar Dewantara pada tahun 1922. Perkembangan awal Perguruan Taman Siswa sampai dengan awal tahun 1930 an merupakan fenomena tersendiri ketika saat itu bekerjasama dengan Sekolah Tari Krida Beksa Wirama di bawah Pangeran Suryadiningrat dan Pangeran Tejakusuma (keduanya putra Sultan Hamengku Buwana VII). Hal ini ternyata mempunyai dampak luas dalam metode didaktik pengajaran anak didik pada Perguruan Taman Siswa setelah tahun 1934 (Majalah Jawa:1938, 23-29).

Salah seorang yang kemudian dikenal dengan Ki Hadi Sukatno merupakan peserta didik yang mendapatkan pembelajaran khusus yang dipersiapkan sebagai seorang guru. Pada akhirnya sosok inilah yang dipercaya Ki Hadjar Dewantara untuk menggarap sebuah genre baru yang dikenal dengan nama Langen Carita. Pak Katno yang ditempa di lingkungan Perguruan Tamansiswa ini sejak duduk di bangku Taman Guru Taman Siswa Yogyakarta pada tahun 1937, telah menekuni, mengasuh, dan menciptakan gending-gending dan tembang (Lagu-lagu Jawa), yang kemudian mengkhususkan diri pada seni permainan anak Jawa (dolanan anak), macapat, dan bacaan buku. Pada tahun 1937 ia mendapat kepercayaan dari Ki Hajar Dewantara untuk memimpin pementasan panembrama (sejenis koor tembang Jawa). Hal ini bagi Hadi Sukatno muda saat itu merupakan kebanggaan tersendiri. Memang demikian, apa yang dikerjakan tidak pernah lepas dari Taman Siswa (Sularto, 1981: 12) .

Ki Hadi Sukatno yang pertama kali dipercaya oleh Ki Hadjar Dewantara untuk menggunakan media langen carita sebagai metode didaktik transfer pengetahuan kepada siswa didik.

\section{METODE}

Kajian artikel ini bersifat kualitatif, dengan menggunakan metode sejarah seni. Sebagaimana metode sejarah, maka di dalam sejarah seni sifat data kualitatif itu dicermati dengan melalui kritik sumber. Langkah kritis ini lazim disebut sebagai langkah heuristik pada metode sejarah. Hal ini dilakukan untuk mendapatkan objektivitas pada kajian. Selain itu pendekatan utama dalam pengkajian ini adalah pendekatan etnokoreologi. Pendekatan ini lazim dilakukan dalam spesifikasi metode sejarah seni yang agak berbeda dengan metode sejarah. Pendekatan etnokoreologi adalah pendekatan dengan menempatkan kedudukan tari sebagai objek multidimensional. Dikarenakan objek tari adalah multidemensi, maka diperlukan pengkajian setiap sisi dimensi yang ada pada objeknya.

Etnokoreologi sebagai payung metodologis diperlukan dalam mendasari bentuk penciptaan Langen Carita sebagai genre drama tari adalah sebuah produk budaya. Ini yang di dalam jagat sosio-kultural diasumsikan sebagai kedudukan tari dalam budaya.

\section{HASIL DAN PEMBAHASAN}

\section{Tinjauan Kesejarahan Genre Sebelum} Lahirnya Langen Carita

Bahasan awal artikel ini didahului dengan sebuah fenomena dramatari opera yang pernah hadir dalam sejarah seni pertunjukan di Jawa. Arti penting bahasan awal ini untuk melihat benang merah yang dapat ditelusuri dari sebuah historisitas dramatari opera. Supadma (2011) menyatakan bahwa bentuk seni pertunjukan tertua dengan nama depan Langen adalah Dramatari Opera Langendriya yang lahir di Yogyakarta seputar 1870-an (2001: 2-3). Langendriya dinyatakan sebagai seni opera tari Jawa yang pertama diciptakan 
di Indonesia. Pencipta dramatari opera ini adalah K.G.P.A.A. Mangkubumi, seorang putra Sultan Hamengku Buwana VI dan menjabat sebagai lurah pangéran serta Ajudan Gubernur Jenderal di Yogyakarta saat itu. Bentuk opera tari ini diciptakan semula bukan untuk tujuan seni pertunjukan. Bahkan, K.G.P.A.A. Mangkubumi selain dikenal mencipta Langendriya juga banyak menciptakan genre tari golek tunggal putri yang menjadi prototipe tari golek gaya Yogyakarta. ${ }^{1}$ Penelitian R.M. Pramutomo sepanjang tahun 2013 hingga awal tahun 2014 secara khusus mengkaji kelahiran dramatari Langendriya ciptaan Pangeran Mangkubumi. Hasil penelitian ini membuktikan bahwa langendriya adalah cikal bakal dramatari opera Jawa dengan kekhususan makna pada namanya 'langen' berarti 'kesukaan' atau 'kegemaran' dan driya yang berarti 'hati' (2014: 43-44). Hal ini jelas menyiratkan nama diri secara tidak langsung memberi narasi pada jenis penyajian yang dibawakan. Atas dasar itu, kata langen yang berarti 'kesukaan' sangat penting artinya bagi genre yang diciptakan.

Pada sumber kesejarahan lain, tulisan editorial Fred Wibowo pada tahun 1981 pernah menyebutkan, bahwa era pasca 1870-an pengaruh nama genre dengan sebutan 'langen' sangat subur bermunculan di Yogyakarta dengan dimotori para seniman bangsawan saat itu. Bisa disebut sebagai kelahiran genre seni pertunjukan yang menggunakan nama 'langen', misalnya Langen Mandra Wanara, LangenWiraga, Langen Asmarasupi, serta Langen Banjaransari yang digagas di Pura Pakualaman (Wibowo ed., 1981: 156-162). Namun demikian, di antara genre tersebut, hanya Langendriya dan Langen Mandra Wanara yang masih dapat diketahui penyajiannya.

\section{Tentang Langendriya}

Dalam tulisan B. Sularto dijelaskan bahwa salah satu bagian pembentukan seni dra- matari opera Jawa lahir di rumah seorang bangsawan tinggi, yang disebut $n$ Dalem $\mathrm{Ka}$ dipatèn (1982: 46-48). Secara prinsip sebenarnya karya dramatari opera Langendriya lebih tepat dikatakan sebagai bentuk kreativitas keluarga bangsawan tinggi yang memenuhi standar inovasi dan eksperimentasi, baik secara fisik maupun teknis-artistik. Untuk alasan ini, dapat dikemukakan, bahwa semula ide penyusunan dramatari opera Langendriya bukan hanya dari K.G.P.A.A. Mangkubumi sendiri. Beranjak dari tradisi macapatan di nDalem Kadipatèn setiap bulan Ramadhan atau Puasa, sebagai pengganti kegiatan latihan menari. Hal ini merupakan kelaziman yang sudah diberlakukan secara tradisional di rumah-rumah para bangsawan tinggi. Salah satu putra Mangkubumi, yakni R.M. Sutandar mengajukan usulan memilih salah satu sastra tulis Serat Damarwulan untuk dibaca bersama-sama saat itu. Langkah ini menumbuhkan ide untuk dilakukan pula dengan cara menggerakkan tangan dan bagian kepala sebagai penambah ekspresi artistik dalam membaca teks tembang dari Serat Damarwulan. Usulan menggerakkan tangan dan bagian kepala ini ditangkap ayahnya agar dikembangkan pada karakter-karakter tertentu sebagai daya hidup muatan cerita Damarwulan.

R.M. Sutandar yang kemudian bergelar K.R.T. Kertanegara ini memohon ayahnya untuk menyaksikan perubahan yang diwujudkan dalam bentuk teks dialog tembang -dengan gerakan tangan maupun leher. Mangkubumi memenuhi permintaan putranya itu dengan menyaksikan peraga tembang memainkan sebuah lakon dari cerita Damarwulan berjudul Jumenengan Nata Dewi Kencanawungu (1982: 46-48). Setelah menyaksikan pertunjukan tembang dengan cerita yang mengambil dari Serat Damarwulan tersebut, Mangkubumi segera menyampaikan koreksi dan kritiknya. Pengamatan Mangkubumi terkonsentrasi kepada kesadaran aspek seni pertunjukan, 
dalam pengertian sebuah sajian genre. Hal ini terutama disampaikan adanya kelemahan pada bentuk gerak dan tata busana serta rincian adegan yang memerlukan penonjolan dramatik tertentu. Atas dasar itu, ia kemudian memerintahkan kepada salah satu putranya yang lain, yakni K.R.T. Wiraguna agar menyusun desain tata busana dan sejumlah properti serta aksesori. Sebuah isyarat disarankan oleh Mangkubumi agar desain busana genre baru tersebut tidak boleh sama dengan desain yang ada di Kraton Yogyakarta.

Untuk memenuhi permintaan ayahnya, Wiraguna segera mengeluarkan ide perpaduan desain gaya Eropa dengan desain bergaya Jawa. Hal ini terutama pada bentuk baju dan hiasan kepala, seperti bulu-bulu dan jamang, atau ikat kepala. Beberapa desain penari peran pria banyak menggunakan desain topi Eropa. Sementara pada busana penari peran putri perpaduan warna Eropa dan Jawa khas Mataraman masih terlihat proporsional. Demikianlah kerja kreatif K.G.P.A.A. Mangkubumi yang dipadukan dengan ide-ide artistik K.R.T. Kertanegara dan sumbangan desain inovatif K.R.T. Wiraguna menjadikan kelengkapan bentuk sajian Langendriya sebagai sebuah genre drama tari opera Jawa mendekati sempurna. Sularto dalam komentarnya menyatakan bahwa Langendriya sebagai bentuk dramatari opera Jawa merupakan salah satu produk berbobot dalam sejarah teater tradisional Nusantara (1982: 48-51).

\section{Lakon Damarwulan}

Penulisan teks lakon Langendriya di Yogyakarta adalah salah satu upaya penyempurnaan dalam bentuk seni pertunjukan yang disempurnakan sesuai dengan format penyajian yang diinginkan kreatornya. Dalam hal ini, K.G.P.A.A. Mangkubumi telah mendapatkan izin khusus dari Sultan Hamengku Buwana VII untuk mengadaptasi Serat Damarwulan yang menjadi koleksi Kraton Yogyakarta (Langendriya Babon Mangkubumen, 1871). Penyusunan naskah dipercayakan kepada K.P.H. Purwodiningrat yang telah merencanakan penyusunannya dalam bentuk tujuh judul episode dari sumber aslinya. Tiap episode merupakan sebuah lakon utuh yang dapat dipertunjukkan selam berjam-jam. Gagasan ini diilhami oleh buku serial Mahabarata dan Ramayana untuk pertunjukan wayang kulit. Judul-judul yang digunakan menurut episode adalah sebagai berikut:

1) Lakon pertama: Jumenengan Nata Dewi Kencanawungu.

2) Lakon kedua: Pejahipun Ranggalawe.

3) Lakon ketiga: Gunjaran.

4) Lakon keempat: Pejahipun Menak Jingga.

5) Lakon kelima: Damarwulan Jumeneng Nata.

6) Lakon keenam: Ratu Wandan Dateng Majapahit.

7) Lakon ketujuh: Panji Wulung Dateng Majapahit.

Perlu diketahui pula, dalam penulisan pertama dibagi dalam beberapa babak, dan setiap babak terdiri atas beberapa rangkaian adegan. Teks lakon juga dilengkapi dengan peraga dalang, para pemeran, dan peraga musik iringannya. Menarik sekali bahwa menurut naskah aslinya, di dalam teks asli lakon yang disusun oleh Purwodiningrat ini, telah dilakukan rincian sebagai berikut.

...rakit, yaitu susunan pelaku, lagon, yaitu
lagu-lagi instrumental yang diperde-
ngarkan, sekar, yaitu lagu-lagu yang diba-
wakan oleh peraga dan dalang, kandha,
yaitu teks narasi monolog yang dibawakan
oleh dalang, pocapan, yaitu teks dialog yang
dibawakan oleh peraga dalam nyanyian
tembang macapat (Langendriya Babon Mang-
kubumen, 1871:2).

Teks lakon lengkap juga dilengkapi dengan balungan lakon atau skema posisi adegan dalam bentuk lampiran atau kerangka lakon, termasuk posisi setiap pelaku di dalam adegan tertentu. Dikarenakan ter- 
dorong rasa terima kasihnya yang besar, maka Purwodiningrat mencantumkan di dalam sampul teks lakon miliknya sebagai bentuk penghargaan seni Langendriya adalah ciptaan ayahnya yakni, K.G.P.A.A. Mangkubumi, seperti syair berikut.

Syair lagu Dandanggula:
"Kangjeng Gusti Pangeran Adipati,
Mangkubumi Opsir pana Oranye,
Nas Opsir krun Siyeme,
Litnan Kolonel mungguh,
Ajidannya Sang Onderkoning,
Mangun Srat Damarwulan,
Winayang ing lagu,
Sekar Gendhing winastanan,
Langendriya saha pinaringan idi,
Dalem Sri Naranata" (1871: 1).

(Kangjeng Gusti Pangeran Adipati, Mangkubumi Officier van Oranje, Nassau, Officier Kroon Siam Sesungguhnya juga Letnan Kolonel Ajudan Sang Onder Koning Mencipta Serat Damarwulan, Dalam bentuk lagu/nyayian, Dengan tembang iringannya namanya, Langendriya dan mendapatkan izin, Sri Sultan (Hamengku Buwana VII).

Mengenai istilah yang kemudian disebut sebagai opera tari atau dramatari opera dalam buku akan dijelaskan sebagai berikut.

Opera dalam perspektif Barat merupakan salah satu genre drama musikal yang di dalamnya menampilkan sebuah lakon dengan dialog menggunakan lagu dan diiringi sebuah orkes lengkap (Sommerset-Ward, 1998: 79-81). Istilah ini jelas tidak sepenuhnya tepat jika penggunaannya dalam konteks Langendriya mengacu dalam istilah opera menurut perspektif Barat. Namun demikian, setidaknya dapat dirujuk dari penggunaan unsur dialog yang menggunakan nyanyian. Hal ini dapat disejajarkan dalam pengertian dramatari opera. Jika di dalam perkembangan opera Barat kemudian muncul genre ballet opera, maka hal ini mungkin lebih dapat mendekati istilah dramatari opera jawa pada genre Langendriya. Dalam arti yang demikian, maka dramatari opera Langendriya merupakan sebuah sandiwara yang percakapan-percakapannya dinyanyikan dan gerak-gerik pelakunya ditarikan. Menurut Sularto, Langendriya merupakan bentuk genre pertama opera tari Jawa dalam perbendaharaan teater tradisional Jawa (1981: 44-45).

Anggapan ini jelas tidak mempunyai rujukan yang dapat dipertanggungjawabkan menurut perspektif yang digunakan. Sebagaimana perspektif seni opera menurut pandangan Barat jelas tidak dapat disepadankan dengan Langendriya. Namun jika itu menunjuk pada seni ballet opera, maka masih agak dekat dalam unsur penyajian dialog yang dinyanyikan. Unsur penyajian menjadi faktor penting dalam mengurai materi kreativitas seseorang.

Hal ini yang pernah pula dibahas dengan sangat baik melalui tulisan Iyus Rusliana (2011). Dalam salah satu uraiannya ditegaskan bahwa sebuah wujud kreativitas akan melekat dengan aspek-aspek visualisasi. Artinya, setiap kemunculan Langendriya dengan segenap visualisasii memiliki dua resiko untuk dicermati kreativitasnya melalui penyajian. Nilai penyajian ada di ranah estetika seremonialisme. Satu hal yang menunjukkan sifat kemiripan dalam bentuk realitas estetis, bahwa kedua tipologi opera baik di dalam perspektif Barat maupun Timur, kedua-duanya merupakan suatu seni pertunjukan elit.

\section{Tentang Langen Mandra Wanara}

Sebuah buku tentang dramatari opera Jawa mungkin dapat menjadi perbandingan. Buku ini berjudul Langen Mandra Wanara: Sebuah Opera Jawa, ditulis oleh Ben Suharto, N. Supardjan, dan Redjomulyo (1999). Pustaka ini merupakan sebuah penelitian kelompok yang berupaya mengungkapkan sebuah genre dramatari opera Jawa Langen Mandra Wanara. Secara menarik Ben Suharto bersama-sama dengan N. Supardjan dan Redjomulyo menyajikan sebuah kupasan lengkap pembentukan dan 
perkembangan seni dramatari opera yang diciptakan oleh K.P.H. Yudanegara III sekitar tahun 1890-an (Suharto dkk., 1999: 1819). Kepentingan pustaka ini untuk menjadi pembanding suatu tinjauan historis penciptaan seni dramatari opera Jawa yang memang lahir di akhir abad ke-19.

Uraian tentang munculnya era seni dramatari opera Jawa sempat diungkapkan melalui kehadiran dramatari opera yang lain, yaitu Langendriya. Hanya saja, acuan penciptaan yang lebih memungkinkan dirujuk dari sumber lisan. Buku ini sangat meyakini awal penciptaan dramatari opera Jawa yang lahir di sekitar tahun 1860-1863 (Suharto dkk., 1999: 16-18). Sementara itu, acuan tentang angka tahun tersebut didapatkan dari prototipe dramatari opera Jawa yang lahir lebih dulu, yakni Langendriya yang disebut-sebut penulis Belanda Th. B. Van Lelyveld. Selain itu, data pendukung yang menyatakan kemunculan $L a$ ngen Mandra Wanara lebih akhir dari $L a-$ ngendriya diuraikan dari hasil wawancara salah satu keturunan K.P.H. Yudanegara III (1999: 19).

Atas dasar itu, buku ini merupakan sumber penting untuk mencermati sebuah era pembentukan seni dramatari opera Jawa yang diawali sejak kelahiran La-ngendriya hingga kelahiran Langen Mandra Wanara gaya Yogyakarta. Jika diperhatikan, kedua genre dramatari opera di atas secara bersamaan muncul dalam sebuah periode pemerintahan Sultan Hamengku Buwana VII (1877-1921). Era ini diyakini sebagai era kelanjutan dari peletakan dasar perkembangan tari gaya Yogyakarta. Pengkajian seni pertunjukan tari Jawa gaya Yogyakarta tidak mungkin mengabaikan era pemerintahan Sultan Hamengku Buwana VII sebagai era yang unik.

Kesamaan penting di antara kedua genre Langendriya dan Langen Mandra Wanara saat itu, bahwa kedua drama tari opera ini diperagakan oleh penari pria, dan dilakukan dengan cara menyerupai sikap berjongkok. Hanya saja, jika posisi lutut pada Langendriya tidak menyentuh lantai, maka di dalam Langen Mandra Wanara posisi lutut diperbolehkan menyentuh lantai. Pada gilirannya kedua genre opera tari, baik Langendriya maupun Langen Mandra Wanara, menjadi genre penting dalam kaitannya dengan status politik penciptanya, serta status lokasi lantai pentas yang melahirkannya. Kajian terhadap kaitan antara status politik dan lantai pentas akan menjadi hal yang menarik, jika didekati dari kehadiran sajian genre pertunjukannya. Atas dasar itu, kepentingan menyelidiki keterkaitan di atas sangat mendorong pembahasan yang lebih mendalam.

Dalam hal ide penciptaan, Langen Mandra Wanara dapat dikatakan tidak serumit Langendriya. Secara materi dramatik, sumber cerita masih bersumber pada wiracarita Ramayana. Dari segi busana masih dapat diacu dari tata busana dalam Wayang Wong, walaupun perbedaan pemakaian topeng telah dimodifikasi di dalam Langen Mandra Wanara. Kemudian, dalam hal teknis presentasi, sajian genre ini hanya mengubah sedikit level yang ada dalam posisi penyangga (kaki) agar tidak sama dengan pola adeg dalam dramatari Wayang Wong. Jika terjadi adegan perang, maka di dalam Langen Mandra Wanara juga lebih memperlihatkan keluwesan dalam hal teknis penyangga atau kaki. Artinya, diperbolehkan menggunakan pola-pola perang seperti dalam Wayang Wong.

Salah satu ciri terpenting dari Langen Mandra Wanara adalah sejumlah besar peran kera ditampilkan di dalam sebuah lakon utuh. Pada karakter kera berjenis kapi (atau kera kecil) tidak disebutkan dalam pernyataan Soedarsono di atas. Tipe khusus dalam karakter kera kecil barangkali tidak begitu penting di dalam dramatari Wayang Wong, namun sangat berarti penting bagi genre Langen Mandra Wanara. Berikut 
ini sebuah acuan tipe karakter kera kecil atau jenis kapi-kapi yang dirujuk dari lakon Kumbakarna Gugur pada tahun 1915 (Arsip Nomor 109, Koleksi KRT. Wiroguno): 1) Jaya Suséna, 2) Jaya Anala, 3) Kapi Ménda, 4) Kapi Kingkin, 5) Kapi Cucak Rawun, 6) Kapi Suraba, 7) Kapi Pramujabahu, 8) Kapi Harimuka, 9) Kapi Truwelun, 10) Kapi Jago, 11) Kapi Cacing, dan 12) Kapi Kumbang.

Dalam acuan lakon yang dipergelarkan tahun 1915 itu, kiranya keduabelas tokoh ini dimiliki pada karakter kera kecil atau kapi. Oleh sebab itu, acuan varian visual gerak pada tipe karakter kera berjenis kapi menjadi penting diungkapkan dalam kajian analisis tipe karakter dramatari opera Langen Mandra Wanara. Dinyatakan, bahwa dalam tradisi gaya Yogyakarta, pola gerak varian visual untuk kera kecil hanya menggunakan ragam miwir asta dhengklik. ${ }^{2}$ Mengikuti periode sejarah pembentukan Langen Mandra Wanara selama dekade awal abad ke-20 maka bisa diduga, bahwa kehadiran karakter kera dalam setiap lakon pertunjukannya mempengaruhi penciptaan lakon-lakon gabungan Ramayana dan Mahabarata di dalam genre seni Wayang Wong di awal tahun 1930an.

\section{Langen Carita Sebuah Genre Dramatari}

Bahasan artikel ini sampai pada uraian tentang mengapa Langen Carita dianggap kelanjutan dari genre sebelumnya yang sudah dulu lahir dalam periode sejarah terdahulu. Dalam kelahiran genre ini tidak dapat dilupakan peran seorang Ki Hadi Sukatno yang mendapat kepercayaan langsung dari Ki Hadjar Dewantara. Saat itu, pada tahun 1929, ia mulai mengenal Taman Siswa yang akhirnya merupakan tempat ia mengabdi hingga akhir hayatnya. Schakel School ini diselesaikannya dalam 4 tahun. Ia juga belajar di Taman Dewasa di Solo sampai tamat, kemudian kembali ke Yogyakarta masuk ke Taman Guru Taman

Siswa Yogyakarta. Selama tiga tahun,
Ki Hadi Sukatno langsung mendapat bimbingan dari Ki Hadjar Dewantara, terutama pengarahan dalam pembinaan kesenian anak-anak (gending dolanan anak-anak). Selain Ki Hadjar Dewantara, nama-nama lain yang turut mempengaruhi proses selanjutnya adalah Ibu Soekemi, Ibu Mangun Sarkara, Ibu Mangun Puspita, dan Ibu Surip (1981: 1-2).

Hadi Sukatno muda selalu digelitik untuk berkreasi, ketika Pendapa Agung Taman Siswa diresmikan pada tahun 1938, ia mementaskan seni permainan anak-anak Cemporowa dan Kembang jagung. Hadi Sukatno juga turut memeriahkan peresmian Pendapa Agung itu, dengan membawakan Tari Hindu koreografi oleh Rusli (pelukis dan anggota Akademi Jakarta). Pengalaman indah waktu muda, yaitu waktu pertama kalinya diperkenalkan memukul gamelan. Ketika menjadi siswa Taman Guru, ia memukul gamelan dengan tidak boleh melihat penarinya, sebab penarinya putri. Ia memukul gamelan dengan membungkuk dan terhalang papan kayu. Tampaknya periode 1930-an inilah yang mejadi tonggak sejarah pendidikan tari untuk putri. Taman Siswa mengawalinya dengan memperbolehkan kaum perempuan. Gurugurunya didatangkan dari sekolah tari Krida Beksa Wirama, termasuk di antaranya GPH. Tejakusuma, BPH. Suryadiningrat, dan RW. Hatmodijaya.

Pengalaman menjadi siswa didik di Taman Guru Perguruan Taman Siswa ini banyak memengaruhi Ki Hadi Sukatno dalam menata fondasi genre baru yang dinamakan Langen Carita. Sekarang ini hanya Taman Siswa saja yang menalurikan kebudayaan itu kepada anak didik. Sebenarnya, demi melestarikan dan mendasari rasa budaya kebangsaannya, seni permainan anak-anak yang mencakup kesenian daerah itu harus tetap hidup. Hanya saja bentuk, isi, dan iramanya yang mesti menyesuaikan gerak zaman. Sifat permainannya 
tetap. Sebab sebagaimana dikemukakan Ki Hadjar Dewantara sifat kebudayaan tidak akan pernah berubah, sekalipun bentuk isi dan iramanya berlainan. Kita bisa mencari jalan pembaharuan supaya seni permainan anak-anak dapat memenuhi selera zaman. Untuk mewujudkan seni permainan anak-anak, seperti jamuran, soyang, dan cublak-cublak suweng mengikuti selera zaman adalah pekerjaan yang sulit. Hal itu disebabkan lingkungan suasananya tidak mendukung. Cara ini adalah sifat didaktik utama ketika mengkreasikan inti pendidikan dalam permainan (dolanan) itu.

Pada gilirannya, dolanan atau seni permainan anak-anak ini adalah prototipe genre Langen Carita yang selanjutnya dikenal sebagai dramatari Langen Carita. Memperhatikan nama sebutan langen dan carita, maka gagasan nama ini mngikuti tradisi peristilahan era sebelumnya. Pada saat para kreator menggunakan nama genre yang baru lahir awal abad ke-19, yakni langen. Arti kata langen yang berarti kesukaan atau kegemaran ditambah imbuhan carita yang berarti 'ceritera'. Sudah agak jelas kini ketika nama Langen Carita memang secara khusus diaplikasikan sebagai genre dramatari bermakna 'kesukaan anak-anak'.

Secara sosiologis, apa yang telah dilakukan Ki Hadi Sukatno merupakan keunggulannya dalam mengaitkan konsep genre dengan variabel-variabel yang terdapat dalam fakta historis (melalui nama genre yang sebelumnya). Pandangan ini aslinya berasal dari pendapat Doyle Paul Johnson. Dinyatakan bahwa menghubungkan suatu nama tertentu dengan suatu benda, pengalaman, atau kejadian adalah langkah yang sangat penting untuk menganalisis dan memahaminya (Johnson, 1987: 35-36). Cara yang sama dapat dilihat dari para ahli yang menemukan gejala baru, apakah itu bahan campuran kimia, bintang, atau proses atomis, maka reaksi yang pertama adalah menentukan nama yang berhubungan de-

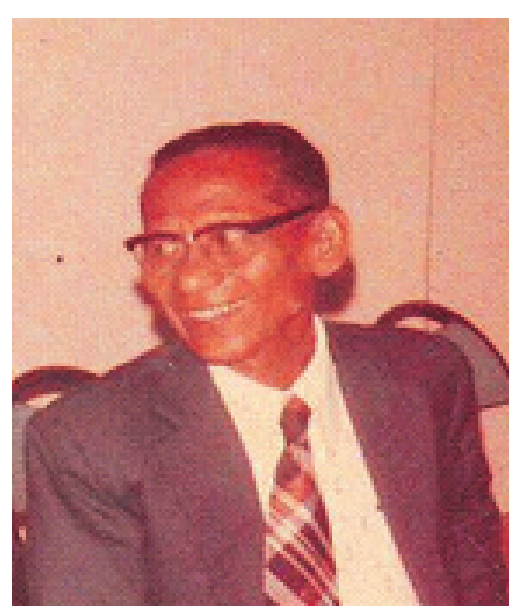

Gambar 1. Profil Ki Hadi Sukatno pada saat masih aktif sebagai guru di Taman Siswa. (Foto Koleksi Museum Taman Siswa Yogyakarta, 1981)

ngannya. Lebih lanjut, menurut Johnson, cara ini mengandung kemungkinan sebuah kreativitas intelektual (Johnson, 1987: 36). Pada akhirnya, argumen terakhir Johnson dalam menentukan sebuah nama, yakni istilah-istilah yang dilahirkan tersebut lebih merupakan cara memandang tertentu terhadap data kehidupan sosial daripada sifat data itu sendiri.

Pandangan Ki Hadi Sukatno dalam menentukan nama sebuah genre kiranya lebih memiliki kesesuaian dalam cara menangkap gejala seni dari pada sifat gejala itu sendiri. Pada gilirannya, dapat dipertegas, bahwa pilihan nama Langen Carita pada saat itu bertendensi ganda. Di satu sisi, ia merupakan simbol artistik pada bentuk sajian atau genre. Di sisi lain, ia sebagai kerangka edukasi, karena tidak dapat dielakkan bahwa setiap lagu dolanan dibawakan peraga anak-anak telah ditentukan muatan makna tuntunannya. Dalam bab ini, sebenarnya proses kreasi dan penyebaran Tembang Dolanan Ki Hadi Sukatno menyerupai apa yang dilakukan oleh RAA. Wiranatakusumah $\mathrm{V}$ di ranah penyebaran Tembang Cianjuran. Rujukan ini sebagaimana dikemukakan Mohammad Yusuf Wiradiredja (2012) ketika mencermati peran tokoh RAA. Wiranatakusumah $\mathrm{V}$ dalam tahun 


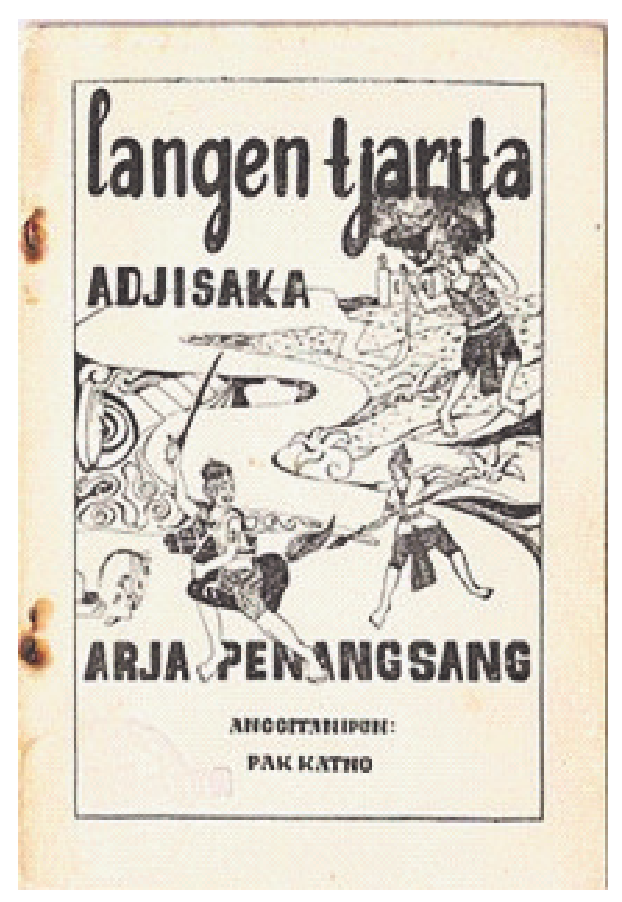

Gambar 2. Naskah Langen Carita berjudul Adji Saka karya Ki Hadi Sukatno (1954). (Koleksi Museum Taman Siswa Yogyakarta)

2012. Lihat gambar 1 dan 2, tentang profil Hadi Sukatno dan Buku Langen Carito.

\section{Lakon Langen Carita}

Mengacu pada indikasi penamaan yang digunakan seperti genre dramatari opera terdahulu, maka nama Langen Carita dapat diartikan sebagai "ceritera kesukaan atau kegemaran anak anak". Cerita awal yang digubah oleh Ki Hadi Sukatno pun menonjolkan sifat heroik dari tokoh yang disajikan. Tampilan sampul naksah yang telah dibukukan pada tahun 1954 adalah cara menunjukkan sosok kepahlawanan daerah yang dijadikan idola anak-anak. Banyak karya Ki Hadi Sukatno yang diperuntukkan Taman Kanak-kanak dan Sekolah Dasar yang telah dibukukan oleh Penerbit Taman Siswa pada tahun 1964 antara lain seperti: Arya Penangsang, Bocah Lola, Jaka Tingkir, Aji Saka, Babat Alas, Kancil Nyolong Timun, Kethek lan Garuda, Bango Thonthong Jatiningsih, Dadung Awuk, Nini Towong, dan Aryo Jipang.

Dua lakon Langen Carita yang dicontohkan, Aji Saka dan Arya Penangsang, merupakan ceritera populer di kalangan anak-anak saat itu. Tokoh Aji Saka dikenal sebagai raja yang menciptakan aksara Jawa dan berhadapan dengan Prabu Dewatacengkar yang berwatak jahat. Sementara itu, Aryo Penangsang adalah seorang berwatak berangasan yang ingin menjadi raja Demak dan berhasil dikalahkan oleh Danang Sutawijaya dalam Babad Tanah Jawa.

Bentuk sajian Langen Carita model awal adalah stereotipe dari Perguruan Taman Siswa yang diciptakan pertama kali oleh Ki Hadi Sukatno. Unsur drama dan unsur tari dipresentasikan dalam bentuk tembang dolanan anak hasil kreasi Ki Hadi Sukatno. Pola gerakan yang dominan bagi peraga tarinya adalah $l u-$ maksana geleng atau tayungan bagi anak lakilaki, dan lumaksana lembehanasta bagi anak perempuan. Jika terdapat adegan perang atau adegan khusus baru dibuatkan koreografi sederhana sebagai representasi dramatik.

Berikut ini adalah daftar lagu dolanan anak yang pernah diciptakan oleh Ki Hadi Sukatno sebagai tembang Langen Carita: Ajar Maca (ABC), Aduh Simbah, Aku Kancil, Aku Kembang, Aku Wis Sekolah, Anti, Ayo Tuku Kluwih, Bang-Bang Wis Rahina, Baris Rampak, Bibis, Brambang-Bawang, Ca-Kanca, Cah Dolan, Doloan Kene, Duh Gusti, E Kowe, E-Kae, Ela Kae, Enthik, Gajah-Gajah, Gobag, Grumegah, Heh Kanca, $\mathrm{Ha} \mathrm{Na} \mathrm{Ca} \mathrm{Ra} \mathrm{Ka}$, Ing Saiki, Iwake Sliweran, Jaranan, Jamuran, Jamur Cepaki, Kae Kae, Kembang jagung, KokKok Petok, Kula Nuwun, Kulo Mboten Dora, Lamun Sayah, Lincek-Lincek, Lindri Telung Kati, Lepetan, Mbok Uwi, Nora Gampang, Ojo Ndomblong, Pitik Walik Jambul, Pyok-Pyok Ngumbahi, Rame-Rame, Sar-Sur Kulonan, Sayuk Rukun, Srengengene, Tak Pancinge, Tak Petik Melati, Tokung-Tokung, Undhi, Widara Kayun, Yo Pada Suka-Suka, dan Yo Prakanca.

\section{Langen Carita Jaka Tingkir dan Nilai Edukasi Seni Masa Kini}

Pada bahasan ini, ceritera Jaka Tingkir dipilih sebagai sumber materi dramatik Langen Carita. Tokoh Jaka Tingkir juga su- 
dah dijadikan sumber cerita sejak tahun 1964 oleh Ki Hadi Sukatno (Koleksi Taman Siswa tahun 1956). Kisah Jaka Tingkir sejak itu pula menjadi idola anak-anak karena kesaktiannya sebagai orang Desa yang berjuang mengadu nasib di kerajaan Demak, hingga akhirnya menjadi pimpinan prajurit kerajaan. Kiranya upaya menghadirkan kembali tokoh Jaka Tingkir dalam bentuk visual koreografi dramatari opera masa kini sangat relevan dengan daya juang dan daya gigih seorang yang ingin mengejar cita-citanya.

Atas dasar itu, maka pilihan menampilkan bentuk garap visual ini menjadi penting dikarenakan muatan pesan yang dituju sebagai penanaman nilai edukasi anak. Dengan kata lain, bahwa sejak tahun 1964 sudah teruji kebertahanan mengidolakan tokoh sejarah lokal sebagai tipe ideal anakanak yang dibangunkan semangat kerja keras dan kegigihannya. Analogi tokoh ideal memang sangat relatif. Namun demikian, jika berkaitan dengan unsur afirmatif penerimaan yang didapat dari kehadiran tokoh Jaka Tingkir dapat berupa transformasi pengetahuan sekaligus transformasi nilai edukasi.

Secara visual penyajian Langen Carita Jaka Tingkir masih memenuhi aspek keseimbangan kreativitas dan gaya penampilan sebagaimana dicermati dalam paparan Rusliana (2014). Hal ini terimplementasi di dalam bentuk garap atau koreografi yang menggunakan medium tubuh penari anakanak. Artinya, kreativitas penciptaan Langen Carita diindikasikan dari kebertahanan elemen visual yang disajikan sebagai genre dramatari opera.

Tiga ranah proses dalam penciptaan $\mathrm{La}$ ngen Carita Jaka Tingkir masih dapat dirujuk dari ranah gagasan, ranah konsep, dan ranah penuangan sekaligus. Pada ranah gagasan, maka aspek yang terimplementasi ditunjukan melalui proses interpretasi dan eksperimentasi. Melalui ranah ini juga dilakukan secara berdampingan, dengan alasan hasil interpretasi pada langkah sebelumnya akan diproses sejalan dengan interpretasinya. Artinya, tahapan eksperimentasi tetap berbasis pada pola interpretasi yang berjalan sebagai inspirasi karya. Di dalam eksperimentasi termasuk akan diujicobakan bentuk-bentuk baru yang mempertimbangkan instrumen tubuh peraga anak-anak yang sangat khas.

Pada ranah konsep sebenarnya kehadiran Langen Carita Jaka Tingkir masih merujuk pada genre dramatari opera sebagaimana yang pernah lahir lebih dulu. Konsep dramatari opera diturunkan sebagai adaptasi genre dramatari opera sebelumnya. Oleh sebab itu, ciri khas lagu tembang dolanan anak dianggap representasi dari sebuah rangsang audio bagi dramatari opera.

Sementara itu, dalam ranah penuangan sudah sangat jelas proses ini menjadi implikasi metodologis dari konstruksinya. Aspek metodologinya dikenal secara lazim sebagai pembentukan. Metode pembentukan adalah aplikasi dari pola-pola teknik estetis dan penuangan. Hal ini merupakan tahapan akhir dari hasil uji coba ketika pola-pola interpretasi dikembangan menjadi pola-pola teknis, pola-pola estetis, dan penuangannya. Hasil penuangan ini menjadi tahapan awal atau prototipe dari penciptaan karya Langen Carita Jaka Tingkir.

Eksplorasi yang tersajikan dalam visualisasi dramatari opera Langen Carita Jaka Tingkir, sangat mengandalkan aspek pendalaman struktur internal kekaryaan. Hal ini yang menjadi warna lain dalam sebuah garap genre dramatari yang dipengaruhi oleh aspek kontemplatif penyusunnya. Wujud kreasi bagi pemilik karya, sengaja melibatkan kekuatan pengolahan ruang batin dunia anak anak yang digagas sebagai visualisasi dalam ekpresi tubuh peraganya. Dalam pandangan metode konstruksi, maka seluruh sisi dalam kekuatan aspek internal Langen Carita Jaka Tingkir itu men- 
jadikannya lapisan-lapisan dramatik yang khas. Setiap kandungan aspek internal dapat diterjemahkan sebagai gaya penampilan (visualisasi bentuk tari) yang mengandalkan kekuatan unsur stimulasi, transformasi, dan unity. Pada gilirannya pesan nilai edukasi anak itu secara inheren tervisualisasi pula dalam bentuknya yang khas.

Sementara itu, nilai edukasi yang diungkap dalam gaya penyajian Langen Carita Jaka Tingkir ini secara keseluruhan mengacu pada tembang dolanan model Ki Hadi Sukatno. Perbedaan isi dalam syair disesuaikan dengan selera anak-anak zaman sekarang. Atas dasar itu, nilai pesan moral dan nilai pesan edukasi ditunjukkan dalam rangsang visual gerak, baik maupun suasana dramatik dalam pertunjukannya. Tabel-tabel yang disajikan di bagian akhir tulisan merupakan sebuah model yang memuat dua bentuk transformasi sistem pengetahuan sekaligus transformasi nilai edukasi anak.

Oleh sebab gaya penampilan pada genre sajian adalah dramatari opera, maka prasyarat khusus peraganya, selain penguasaan teknik gerak juga teknik vokal berupa tembang. Pola teknis pada gerak berhubungan dengan kualifikasi estetis koreografis, sedangkan pola teknis vokal berhubungan dengan kualifikasi karakter yang dibunyikan dalam syair tokoh tertentu. Bahkan, tidak jarang pula pola khusus berupa gerak penguat ekspresi atau baton signal digunakan sebagai elemen pembentuk suasana dramatik. Pola khusus baton signal atau gerakan penguat ekspresi sebenarnya berasal dari teori anthropology of human movement milik Desmond Morris (1977: 189-199). Dalam bukunya Manwatching: A Field Guide to Human Behaviors, Morris sebenarnya melakukan identifikasi perilaku manusia dan gerakan yang menjadi unsur asal gerakan. Pola khusus berupa baton signal sangat penting dalam genre dramatari opera.

Pola yang sama juga menjadi pola khusus melalui segmen-segmen yang terdapat pada genre dramatari opera pendahulunya. Suatu contoh dalam Langendriya, pada saat dialog antar tokoh memerlukan gerakan penguat ekspresi, maka tidak jarang tokoh yang terlibat mengangkat lengan dan mengucapkan dialog tembang. Demikian pun dalam genre Langen Mandra Wanara, kekuatan tembang yang berisi dialog pesan oleh peraganya disertai gerakan penguat ekspresi atau baton signal. Biasanya bentukbentuk baton signal muncul saat dialog tembang memerlukan penguat dalam pesan petuah, pesan keyakinan diri sang tokoh, atau pesan konflik dan perdebatan.

Pada Langen Carita Jaka Tingkir, hal ini dihadirkan dalam bentuk ekspresi peraga anak-anak. Sifat sugestif yang menjadi dampak dari gerakan baton signal akan member bobot karakter pada tokoh yang dibawakan. Tidak jarang pula sifat sugestif ini member warna natural ketika usia anak membawakan gerakan baton signal sebagai upaya memenuhi tuntutan peran pada tokoh tertentu. Selain pola khusus gerakan baton signal, ciri khusus lainnya dalam setiap segmen keseluruhan Langen Carita Jaka Tingkir adalah dimunculkannya pola theatrical mimicry atau gerak maknawi teatrikal. Secara umum, hampir semua genre dramatari opera menghendaki elemen gerak teatrikal mimikri. Selain kekuatan yang bersifat teatrikal, maka gerakan maknawi teatrikal adalah faktor penentu dalam menuntun nilai edukasi dan pesan moral dari setiap segmen adegan.

Melalui pola khusus gerak maknawi teatrikal ini komunikasi pesan moral, pesan edukasi, dan pesan solidaritas dunia anak hadir secara natural. Atas dasar itu kekuatan aspek penyajian yang dimaksud dalam pernyataan Rusliana pada konteks dramatari opera Langen Carita tidak sekedar menjadi aspek koreografi, melainkan juga aspek bentuk. Hal ini dikarenakan setiap bentuk atau genre memiliki implikasi penyajian dan komunikasi sekaligus. 
Tabel 1. Deskripsi penyajian dalam adegan Dolanan Bocah

\begin{tabular}{|c|c|c|}
\hline Pesan Moral & Pesan Edukasi & Pesan Solidaritas \\
\hline $\begin{array}{l}\text { Permainan adalah dunia anak- } \\
\text { anak yang selalu mencermin- } \\
\text { kan keceriaan. }\end{array}$ & $\begin{array}{l}\text { Dolanan Bocah dalam makna per- } \\
\text { mainan dunia anak anak mempu- } \\
\text { nyai daya imajinasi untuk me- } \\
\text { nyeimbangkan nalar dan rasa. }\end{array}$ & $\begin{array}{l}\text { Permainan anak-anak membe- } \\
\text { rikan rasa kebersamaan dan } \\
\text { kesetaraan alam pikir dan sa- } \\
\text { ling bergantung. }\end{array}$ \\
\hline
\end{tabular}

Tabel 2. Deskripsi bentuk gerak dalam adegan Dolanan Bocah

\begin{tabular}{|c|c|c|c|c|}
\hline $\begin{array}{l}\text { Bentuk-bentuk } \\
\text { baton signal }\end{array}$ & $\begin{array}{l}\text { Bentuk-bentuk } \\
\text { gesture }\end{array}$ & $\begin{array}{l}\text { Bentuk-bentuk } \\
\text { imitatif }\end{array}$ & $\begin{array}{l}\text { Volume } \\
\text { Gerak }\end{array}$ & $\begin{array}{l}\text { Properti, Atribut, } \\
\text { dan Aksesoris }\end{array}$ \\
\hline & $\begin{array}{l}\text { Trained gesture atau } \\
\text { gerak maknawi } \\
\text { yang dapat dilatih }\end{array}$ & $\begin{array}{l}\text { Gerak tiruan } \\
\text { menyapa. }\end{array}$ & $\begin{array}{l}\text { Volume sedang } \\
\text { dan kecil. }\end{array}$ & - \\
\hline & $\begin{array}{l}\text { Teatrical mimicry } \\
\text { atau gerak mak- } \\
\text { nawi teatrikal. }\end{array}$ & $\begin{array}{l}\text { Gerak tiruan } \\
\text { bertengkar. }\end{array}$ & $\begin{array}{l}\text { Volume sedang } \\
\text { dan kecil. }\end{array}$ & - \\
\hline $\begin{array}{l}\text { Gerak penguat } \\
\text { presi tangan dar } \\
\text { jari-jari }\end{array}$ & & & & \\
\hline
\end{tabular}

Tabel 3. Deskripsi penyajian dalam adegan Buaya

\begin{tabular}{lll}
\hline \multicolumn{1}{c}{ Pesan Moral } & \multicolumn{1}{c}{ Pesan Edukasi } & \multicolumn{1}{c}{ Pesan Solidaritas } \\
\hline Figur buaya ditafsirkan se- & Figur buaya dalam sumber tradi- & Garap koregrafi tari buaya \\
bagai buaya betina. Sebenar- & sional dianggap penghalang ja- & adalah pola-pola kerjasama \\
nya secara khusus tidak ada & lan bagi tokoh Jaka Tingkir, na- & dalam koreografi kelompok. \\
pesan moral dalam figur ini & mun nilai yang ingin ditunjukan & \\
hanya lebih sebagai pertim- & adalah seberapapun berat halang- \\
bangan teknis. & an haruslah dilalui. & \\
\hline
\end{tabular}

Tabel 4. Deskripsi bentuk gerak dalam adegan Buaya

\begin{tabular}{|c|c|c|c|c|}
\hline $\begin{array}{l}\text { Bentuk-bentuk } \\
\text { baton signal }\end{array}$ & $\begin{array}{l}\text { Bentuk-bentuk } \\
\text { gesture }\end{array}$ & $\begin{array}{l}\text { Bentuk-bentuk } \\
\text { imitatif }\end{array}$ & $\begin{array}{l}\text { Volume } \\
\text { Gerak }\end{array}$ & $\begin{array}{l}\text { Property, Atribut, } \\
\text { dan Aksesoris }\end{array}$ \\
\hline & $\begin{array}{l}\text { Gerakmaknawi } \\
\text { teatrikal. }\end{array}$ & & $\begin{array}{l}\text { Volume gerak } \\
\text { sedang dan } \\
\text { lebar. }\end{array}$ & - \\
\hline & $\begin{array}{l}\text { Gerakmaknawi } \\
\text { teatrikal. }\end{array}$ & $\begin{array}{l}\text { Gerak tiruan buaya } \\
\text { berjalan, dan melata }\end{array}$ & $\begin{array}{l}\text { Volume gerak } \\
\text { sedang dan } \\
\text { lebar. }\end{array}$ & - \\
\hline $\begin{array}{l}\text { Gerak penguat } \\
\text { ekspresi berdeba } \\
\text { tangan dan jari-j }\end{array}$ & & & & \\
\hline
\end{tabular}


Tabel 5. Deskripsi penyajian dalam adegan Joko Tingkir perang melawan Buaya

\begin{tabular}{lll}
\hline \multicolumn{1}{c}{ Pesan Moral } & \multicolumn{1}{c}{ Pesan Edukasi } & \multicolumn{1}{c}{ Pesan Solidaritas } \\
\hline Joko Tingkir Perang mela- & Joko Tingkir Perang & Joko Tingkir Perang melawan Buaya \\
wan Buaya memuat pesan & melawan Buaya me- & memuat pesan solidaritas yang dicermin- \\
moral setiap meraih cita-cita & miliki pesan edukasi & kan dengan keinginan bersama akan men- \\
harus melewati berbagai & agar setiap manusia jadi nyata jika didukung oleh sebagian be- \\
ujian. & mempunyai cita cita & sar pengikutnya. \\
Dilanjutkan menyeberang & untuk menuju masa & Dalam hal ini figur buaya digambarkan \\
Bengawan memiliki pesan & depan & semula berperang dan akhirnya mendu- \\
moral terlewatinya sebuah & & kung saat Jaka Tingkir menyebrang sungai. \\
halangan dan batu ujian. & & \\
\hline
\end{tabular}

Tabel 6. Deskripsi bentuk gerak dalam adegan Joko Tingkir perang melawan Buaya

\begin{tabular}{lllll}
\hline $\begin{array}{l}\text { Bentuk-bentuk } \\
\text { baton signal }\end{array}$ & $\begin{array}{l}\text { Bentuk-bentuk } \\
\text { gesture }\end{array}$ & $\begin{array}{l}\text { Bentuk-bentuk } \\
\text { imitatif }\end{array}$ & $\begin{array}{l}\text { Volume } \\
\text { Gerak }\end{array}$ & $\begin{array}{l}\text { Property, Atribut, } \\
\text { dan Aksesoris }\end{array}$ \\
\hline $\begin{array}{l}\text { Tidak ada gerak } \\
\text { penguat ekspresi }\end{array}$ & $\begin{array}{l}\text { Volume } \\
\text { gerak } \\
\text { lebar }\end{array}$ & \\
& $\begin{array}{l}\text { Gerak maknawi yang } \\
\text { dilatih atau trained } \\
\text { gesture }\end{array}$ & $\begin{array}{l}\text { Volume } \\
\text { gerak } \\
\text { lebar }\end{array}$ & \\
\hline
\end{tabular}

Tabel 7. Deskripsi penyajian dalam adegan Dadung Awuk

\begin{tabular}{lll}
\hline \multicolumn{1}{c}{ Pesan Moral } & \multicolumn{1}{c}{ Pesan Edukasi } & \multicolumn{1}{c}{ Pesan Solidaritas } \\
\hline Dadung Awuk dan Prajurit me- & Dadung Awuk dan Prajurit & Dadung Awuk dan Prajurit me- \\
miliki pesan moral tidak baik & memiliki pesan edukasi agar miliki pesan solidaritas bahwa \\
menjadi sombong atau arogan, & manusia jika sudah tercapai capaian cita-cita kita tidak le- \\
dan berkuasa semaunya. & $\begin{array}{l}\text { keinginan dan cita-citanya agar } \\
\text { tidak sombong atau arogan. }\end{array}$ & $\begin{array}{l}\text { pas dari dukungan dan do- } \\
\text { rongan orang lain. }\end{array}$ \\
\hline
\end{tabular}

Tabel 8. Deskripsi bentuk gerak dalam adegan Dadung Awuk

\begin{tabular}{|c|c|c|c|c|}
\hline $\begin{array}{l}\text { Bentuk-bentuk } \\
\text { baton signal }\end{array}$ & $\begin{array}{l}\text { Bentuk-bentuk } \\
\text { gesture }\end{array}$ & $\begin{array}{l}\text { Bentuk-bentuk } \\
\text { imitatif }\end{array}$ & $\begin{array}{l}\text { Volume } \\
\text { Gerak }\end{array}$ & $\begin{array}{l}\text { Property, Atribut, } \\
\text { dan Aksesoris }\end{array}$ \\
\hline \multirow[t]{2}{*}{$\begin{array}{l}\text { Tidak ada gerak } \\
\text { penguat ekspre- } \\
\text { si khusus }\end{array}$} & & & $\begin{array}{l}\text { Volume ge- } \\
\text { rak cende- } \\
\text { rung lebar }\end{array}$ & - \\
\hline & $\begin{array}{l}\text { Gerak maknawi yang } \\
\text { dilatih atau trained } \\
\text { gesture }\end{array}$ & $\begin{array}{l}\text { Gerak tiruan prajurit } \\
\text { berlatih } \\
\text { Gerak tiruan prajurit } \\
\text { berolah tubuh } \\
\text { Gerak tiruan prajurit } \\
\text { berperang }\end{array}$ & $\begin{array}{l}\text { Volume ge- } \\
\text { rak cende- } \\
\text { rung lebar }\end{array}$ & - \\
\hline
\end{tabular}


Tabel-tabel di atas menjelaskan proses terjadinya transformasi bentuk dan nilai serta fungsi edukasi dalam Langen Carita Jakatingkir dalam sejumlah adegan pertunjukan yang dimainkan dalam konteks masa kini sebagaimana telah dijelaskan sebelumnya.

\section{SIMPULAN}

Langen Carita merupakan sebuah kreasi baru dari jenis penyajian dramatari opera Jawa. Dari asal nama diri yang merujuk pada jenis penyajian terdahulu, maka $L a-$ ngen Carita sangat dipengaruhi oleh aspek teatrikal dari Langendriya dan Langen Mandra Wanara. Materi dramatik Langen Carita diambilkan dari cerita daerah setempat terutama berkaitan dengan pahlawan tradisional. Ciri penanda bentuk dramatari opera Jawa pada Langen Carita terdapat pada teks lagi dolanan anak yang disesuaikan dengan peraga anak-anak. Selain itu, unsur gerakan pada peraganya juga mengikuti irama tembang dolanan anak-anak yang dibawakan.

Sudah sewajarnya Ki Hadi Sukatno yang ditempa di lingkungan Perguruan Taman Siswa ini, sejak duduk di bangku Taman Guru Taman Siswa Yogyakarta pada tahun 1937, telah menekuni, mengasuh, dan menciptakan gending-gending dan tembang (lagu-lagu Jawa), yang kemudian mengkhususkan diri pada seni permainan anak Jawa (dolanan anak), macapat, dan bacaan buku. Nilai edukasi anak sudah melekat sejak penciptaan lagu dolanan oleh Ki Hadi Sukatno digunakan sebagai media ajar.

Kehadiran garap Langen Carita Jaka Tingkir sebagai edukasi seni usia anak berupaya menjawab kebutuhan sarana sistem pengetahuan yang dikemas dalam visualisasi dramatari opera masa kini. Hal mana secara genre tidak lepas dari cikal bakal dramatari opera Langen Carita sejak zaman Taman Siswa dulu. Penciptaan Langen Carita Jaka Tingkir masih menggunakan tembang dolanan anak dan dipadu dengan tembang macapat. Aspek-aspek visualisasi koreografi dan karakter usia anak-anak menjadikan ciri dramatari opera ini sarat pesan moral dan edukasi. Pada gilirannya, dramatari opera Langen Carita merupakan sebuah genre seni pertunjukan yang identik dengan edukasi anak.

\section{Catatan Akhir}

${ }^{1}$ Tidak kurang dari berbagai genre tari golek tunggal putri diciptakan selama hidupnya, antara lain: Golek Gambyong, Golek Gegar Mayang, Golek Pocung Kethoprak, Golek Surengrana, Golek Layung Seta, Golek Ngreni, Golek Jangkung Kuning, Golek Gambir Sawit, Golek Calunthang, Golek Kutut Manggung, dan sebagainya.

${ }^{2}$ Keterangan ini diperoleh dari KRT. Pujaningrat dalam sebuah wawancara tanggal 11 Agustus 2015. Asumsi adanya visualisasi ragam gerak kera kapi dimungkinkan berpengaruh besar bagi kemunculan variasi ragam gerak yang digunakan dalam pertunjukan Wayang Wong tahun 1934-1935. Pada tahun-tahun itu Kraton Yogyakarta mulai menggubah materi dramatik campuran Mahabarata dan Ramayana dalam bentuk lakon Semar Boyong, Rama Nitik, dan Rama Nitis (ketiga-tiganya digubah semasa pemerintahan Sultan Hamengku Buwana VIII).

\section{Daftar Pustaka}

NN. Arsip Nomor 109 Koleksi Kantor Arsip dan Dokumen K.R.T. Wiraguna, tahun 1915.

NN. Langendriya Babon Mangkubumen 1871, Koleksi KRT. Pujaningrat

NN. (2004). Sarasilah Paguyuban Kadangkadeyan Mangkubumen. (Koleksi Kantor Arsip dan Dokumen KRT. Wiroguno, Yogyakarta).

Morris, D. (1977). Manwatching: A Field Guide to Human Behaviors. New York: Harry N' Abrahms.

Paul, J. D. (1987). Teori Sosiologi Klasik dan Moderen. Jakarta: P.T. Gramedia.

Pramutomo, R.M. dkk. (2014). Langendriya: Dramatari Opera Gaya Yogyakarta. Yogyakarta: Dinas Kebudayaan DIY.

Rusliana, I. (2011). Kreativitas dan Penyajian Tari Sunda. Panggung, 21 (04): 151-165.

Sommerset-Ward, R. (1998). The Story of Opera. New York and London: Henry Abrahms. 
Suharto, B. dkk. (1999). Langen Mandra Wanara: Sebuah Opera Jawa. Yogyakarta: Yayasan Untuk Indonesia.

Sularto, B. (1981). K.G.P.A. Mangkubumi: Hasil Karya dan Pengabdiannya. Yogyakarta: Departmen Pendidikan dan Kebudayaan DIY.
Supadma. (2011). Langendriya dan Serat Damarwulan: Sebuah Kajian Intertekstualitas. Mudra, 26 (01), 25-35.

Wiradiredja. M. Y. (2012). Peranan RAA. Wiranatakusumah V Dalam Penyebaran Tembang Sunda Cianjuran, Panggung, 22 (03), 283-292. 